\title{
The prevalence of intestinal dysbiosis in patients referred for antireflux surgery
}

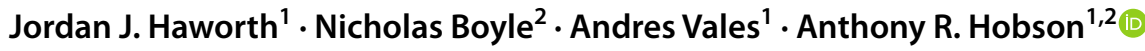

Received: 26 May 2020 / Accepted: 3 December 2020 / Published online: 21 January 2021

(c) The Author(s) 2021

\begin{abstract}
Background Prior to antireflux surgery, most patients with symptoms of gastroesophageal reflux disease (GERD) have been taking long-term proton pump inhibitors (PPIs). PPIs have been shown to cause changes to the intestinal microbiota, such as small intestinal bacterial overgrowth (SIBO), which is characterised by symptoms of gas bloating. Patients undergoing antireflux surgery are not routinely screened for SIBO, yet many patients experience gas-related symptoms postoperatively. Methods Data from consecutive patients $(n=104)$ referred to a speciality reflux centre were retrospectively assessed. Patients underwent a routine diagnostic workup for GERD including history, endoscopy, oesophageal manometry and 24-h pH-impedance monitoring off PPIs. Intestinal dysbiosis was determined by hydrogen and methane breath testing with a hydrogen-positive result indicative of SIBO and a methane-positive result indicative of intestinal methanogen overgrowth (IMO).

Results $60.6 \%$ of patients had intestinal dysbiosis (39.4\% had SIBO and 35.6\% had IMO). Patients with dysbiosis were more likely to report bloating ( $74.6 \%$ vs $48.8 \% ; P=0.01)$ and belching $(60.3 \%$ vs $34.1 \% ; P=0.01)$. The oesophageal acid exposure time and number of reflux episodes were similar between dysbiosis and non-dysbiosis groups, but patients with dysbiosis were more likely to have a positive reflux-symptom association $(76.2 \%$ vs $31.7 \% ; P<0.001)$, especially for regurgitation in those with SIBO $(P=0.01)$. Hydrogen gas production was significantly greater in patients with a positive reflux-symptom association for regurgitation (228.8 ppm vs $129.1 \mathrm{ppm}, P=0.004$ ) and belching (mean AUC $214.8 \mathrm{ppm}$ vs $135.9 \mathrm{ppm}, P=0.02$ ). Conclusions The prevalence of intestinal dysbiosis is high in patients with GERD, and these patients are more likely to report gas-related symptoms prior to antireflux surgery. Independently, SIBO may be a contributory factor to refractory reflux symptoms and gas bloating in antireflux surgery candidates.
\end{abstract}

Keywords Gastroesophageal reflux disease (GERD) · Proton pump inhibitors (PPIs) · Small intestinal bacterial overgrowth (SIBO) - Bloating

Indications for antireflux surgery include inadequate symptomatic response to high-dose acid suppression, typically proton pump inhibitors (PPIs), or a desire to cease drug therapy due to quality of life considerations. Most patients undergoing antireflux surgery will have been taking PPIs for many years. Indeed, a recent study in patients randomised to antireflux surgery or high-dose PPI therapy reported that the average duration of PPI use for all patients was 8.4 (range $0.3-35)$ years [1].

\footnotetext{
Anthony R. Hobson

anthony@thefunctionalgutclinic.com

1 The Functional Gut Clinic, London W1G 6NB, UK

2 RefluxUK, London, UK
}

The most common postoperative complaints following antireflux surgery are dysphagia and symptoms related to gas-bloat syndrome, although gas-related symptoms are more frequently reported than heartburn, epigastric pain, and dysphagia at 5 years postoperatively [2-4]. Gas-bloat syndrome is characterised by the inability to belch, postprandial bloating and flatulence. Outcomes of bloating and the inability to belch are also considered to be less acceptable than dysphagia by antireflux surgery candidates [5] and may be a reason to decline surgery during the consenting process. While these symptoms are thought to be caused by a supercompetent fundoplication that prevents gastric venting, the mechanism for gas-bloat remains unclear.

A multitude of adverse events have been associated with long-term PPI use despite poor evidence and a lack of 
randomised trials [6]. These include dementia, chronic kidney disease, pneumonia, bone fracture, hypomagnesaemia, vitamin B12 deficiency, gastric cancer, Clostridium difficile infection and changes to the gut microbiome.

There is compelling evidence which shows that PPI therapy alters the composition of gut microflora to one that is populated with oropharyngeal commensals and predisposed to enteric gut infections [7, 8]. The use of PPIs has a more profound change on the gut microbiota when compared to antibiotics or any other drug, with a significant shift of the gut microbiome in PPI users towards the oral microbiome [8]. PPIs reduce the acidity of the stomach, thereby reducing the powerful antimicrobial effect of stomach acid and allowing colonisation of microorganisms in the proximal gut. Several studies have demonstrated that PPI use is associated with small intestinal bacterial overgrowth (SIBO) [9-11].

In SIBO, there is an altered or increased presence of bacteria in the small bowel defined by a bacterial count of $>10^{3}$ colony forming units per $\mathrm{mL}$ [12]. SIBO is manifested by symptoms of diarrhoea, postprandial bloating and flatulence, which are consequent to an increase in gas production by bacterial fermentation in the small bowel. Hydrogen and methane breath testing (HMBT) is a simple, non-invasive and a widely accepted means of detecting SIBO. It utilises the detection of hydrogen $\left(\mathrm{H}_{2}\right)$ and methane $\left(\mathrm{CH}_{4}\right)$ gas, which are specific biomarkers of endogenous bacterial fermentation [13]. Excessive methane production is due to an overgrowth of archaea, as opposed to bacteria. Since archaea may overgrow throughout the intestinal tract, the term "intestinal methanogen overgrowth (IMO)" is appropriate to allow a distinction to be made [14].

The cause of gas-bloat symptoms following antireflux surgery may be related to a disruption of the intestinal microbiota, including SIBO, and PPI use may be the precipitant of this. The aim of this retrospective study was to utilise HMBT for the identification of intestinal dysbiosis in patients with PPI-refractory symptoms of GERD who were being reviewed for antireflux surgery.

\section{Methods}

This retrospective database study included patients referred from secondary care to a speciality reflux centre from March 2017 to September 2019. All patients were evaluated by a surgeon and underwent 24-h oesophageal $\mathrm{pH}$-impedance monitoring with a view to potentially undergoing antireflux surgery. All patients who also completed a lactulose hydrogen and methane breath test were selected and the data reviewed. Exclusion criteria included patients younger than 18 years old, use of antibiotics ( $<4$ weeks), a history of organic gastrointestinal disease, and previous gastrointestinal surgery. Patients with a hiatal hernia were not excluded.
All patients included in this study had provided written informed consent at the time of testing that their data could be used anonymously for research and audit purposes.

\section{Lactulose HMBT}

Patients were provided with preliminary instructions before the test. Antibiotics were avoided for 4 weeks before, probiotics and all forms of laxatives were avoided for 1 week before, and anti-diarrhoeal medications were avoided for 2 days before. On the day prior to testing, patients followed a low fermentable diet which included white bread, white rice, white potatoes without skin, maximum two eggs, baked or grilled chicken and white fish, water, unflavoured black tea or coffee and one tablespoon of butter or margarine. No other foods were permitted. A 12-h fast was performed before the test. On the day of the test, patients were advised to brush teeth, avoid smoking or chewing gum and limit to one glass of water. Physical activity was prohibited during the test to keep carbon dioxide $\left(\mathrm{CO}_{2}\right)$ levels constant.

A single baseline breath sample was collected before ingestion of $10 \mathrm{~g}$ of lactulose dissolved in $200 \mathrm{~mL}$ of water. Thereafter, a further 9 breath samples were collected every $15 \mathrm{~min}$. Breath samples were collected in exetainer vials (Labco, UK), and concentrations of $\mathrm{H}_{2}, \mathrm{CH}_{4}$ and $\mathrm{CO}_{2}$ were measured by gas-chromatography (Agilent, Santa Clara, CA). Intestinal dysbiosis was defined by a positive result for SIBO and/or positive result for IMO. A rise in $\mathrm{H}_{2} \geq 10 \mathrm{ppm}$ from baseline occurring within $60 \mathrm{~min}$ was indicative of SIBO [15], and a measurement of $\mathrm{CH}_{4} \geq 10 \mathrm{ppm}$ in any single breath sample during the test was indicative of IMO [12]. Area under the concentration-time curve (AUC) for $\mathrm{H}_{2}$ and $\mathrm{CH}_{4}$ was calculated by adding the $\mathrm{CO}_{2}$-adjusted levels using the trapezoid method.

\section{Reflux monitoring}

Patients were instructed to discontinue PPI medications for 5 days before the test, $\mathrm{H}_{2}$ receptor antagonists for 2 days before the test and liquid alginates 1 day before the test. Patients were required to fast for at least $4 \mathrm{~h}$ before the test. High-resolution oesophageal manometry was performed prior to 24-h oesophageal $\mathrm{pH}$-impedance monitoring in order to locate the lower oesophageal sphincter (LES) for accurate placement of the distal $\mathrm{pH}$ sensor $5 \mathrm{~cm}$ above the LES. A pH-impedance catheter and ZepHr recorder device (Diversatek, Milwaukee, WI) was used to detect acid, nonacid and gaseous reflux events. An abnormal oesophageal acid exposure time (AET) was defined by an AET $>4.0 \%$, which is a borderline abnormal result according to the Lyon Consensus [16]. The patient's most troublesome symptoms (up to a maximum of 3 ) were recorded using buttons on the $\mathrm{pH}$ recorder for reflux-symptom association, but lower 
gastrointestinal symptoms (nausea, bloating and abdominal pain) were not assessed for reflux-symptom association. A positive reflux-symptom association was determined by a symptom index of $\geq 50 \%$ together with a symptom association probability of $\geq 95 \%$.

\section{Statistical analysis}

Data were collected retrospectively from the patient's referral letter, history, HMBT report and 24-h pH-impedance data. Continuous variables were expressed as means \pm standard deviation, unless otherwise stated. Discrete variables were expressed as numbers and percentages. The means were compared by student's $t$-tests. The association between characteristics was determined by the Pearson chi-squared tests. A $P$ value of $<0.05$ was considered statistically significant. All statistical analyses were performed using IBM SPSS Statistics 24.

\section{Results}

104 patients were included in this study. The mean age of the study population was 51 (range 21-78) years, and $51.9 \%$ were male. All patients had been taking gastric acid antisecretory medication for at least 6-months prior to investigation and still reported at least one typical symptom of GERD (heartburn, regurgitation and/or chest pain). The demographic information is summarised in Table 1. Around half of the patients reported gas-related symptoms with excessive belching in $50.0 \%$ and bloating in $64.4 \%$. In total, $63 / 104$ patients $(60.6 \%)$ had intestinal dysbiosis as determined by HMBT. The proportion of patients with a $\mathrm{H}_{2}$-positive (SIBO) and $\mathrm{CH}_{4}$-positive (IMO) breath test was $39.4 \%$ and $34.6 \%$, respectively. The prevalence of concomitant SIBO and IMO was $13.4 \%$.

A total of 33 patients had an abnormal acid exposure time on oesophageal pH-metry (Table 1), and this was not statistically significant between the dysbiosis and non-dysbiosis groups $(P>0.05)$. The mean number of reflux events was slightly higher $(61.5 \pm 37.0)$ in patients with dysbiosis than in those without $(50.4 \pm 35.2)$, but this was not statistically significant $(P>0.05)$. The mean DeMeester score was not different between dysbiosis and non-dysbiosis groups $(P>0.05)$. A total of 61 patients had a positive refluxsymptom association, and this was statistically significant between dysbiosis and non-dysbiosis groups $(P<0.001)$. Patients with a positive reflux-symptom association had significantly more $\mathrm{H}_{2}$ production on HMBT than those without (mean AUC 199.3 ppm vs 99.2 ppm; $P=0.001$ ).
Table 1 Demographic and 24-h oesophageal $\mathrm{pH}$-impedance characteristics for patients with a negative HMBT and patients with a positive HMBT for intestinal dysbiosis

\begin{tabular}{lllr}
\hline & Negative HMBT & Positive HMBT & $P$ value* \\
\hline$N$ & $41(39.4)$ & $63(60.6)$ & \\
Male & $19(46.3)$ & $35(55.6)$ & 0.36 \\
Mean (SD) age in years & $53.2 \pm 14.3$ & $49.2 \pm 14.1$ & 0.16 \\
Symptoms & & & \\
Heartburn & $24(58.5)$ & $42(66.7)$ & 0.40 \\
Regurgitation & $22(53.7)$ & $34(54.0)$ & 0.98 \\
Chest pain & $11(26.8)$ & $23(36.5)$ & 0.30 \\
Cough & $13(31.7)$ & $16(25.4)$ & 0.48 \\
Belching & $14(34.1)$ & $38(60.3)$ & 0.01 \\
Nausea & $9(22.0)$ & $18(28.6)$ & 0.45 \\
Bloating & $20(48.8)$ & $47(74.6)$ & 0.01 \\
Abdominal pain & $15(36.6)$ & $30(47.6)$ & 0.27 \\
AET $>4.0 \%$ & $10(24.4)$ & $23(36.5)$ & 0.19 \\
Mean (SD) number of reflux events & $50.4 \pm 35.2$ & $61.5 \pm 37.0$ & 0.13 \\
Mean (SD) DeMeester score & $13.6 \pm 18.5$ & $12.3 \pm 17.8$ & 0.72 \\
Positive reflux-symptom association & $13(31.7)$ & $48(76.2)$ & $<0.001$ \\
Heartburn SAP & $5(12.2)$ & $14(22.2)$ & 0.20 \\
Regurgitation SAP & $6(14.6)$ & $24(38.1)$ & 0.01 \\
Chest pain SAP & $1(2.4)$ & $3(4.8)$ & 0.55 \\
Cough SAP & $3(7.3)$ & $1(1.6)$ & 0.14 \\
Belching SAP & $6(14.6)$ & $23(36.5)$ & 0.02 \\
\hline Values are expressed as & & &
\end{tabular}

Values are expressed as numbers (percentages) unless stated otherwise

$H M B T$ hydrogen and methane breath test, $A E T$ acid exposure time, $S A P$ symptom association probability *Using Student's $t$ test and $\chi^{2}$ test between negative and positive HMBT groups 
A positive reflux-symptom association for regurgitation and belching was more frequent in those with a positive HMBT compared to those with a negative HMBT $(P=0.01$ and $P=0.02$, respectively). Further analysis determined that breath $\mathrm{H}_{2}$ production was greater in patients with a positive reflux-symptom association for regurgitation (mean AUC $228.8 \mathrm{ppm}$ vs $129.1 \mathrm{ppm}, P=0.004$ ) and belching (mean AUC $214.8 \mathrm{ppm}$ vs $135.9 \mathrm{ppm} ; P=0.02)$. The AUC for $\mathrm{CH}_{4}$ was not different between groups $(P>0.05)$. Symptoms and oesophageal $\mathrm{pH}$-metry findings for patients with a $\mathrm{H}_{2}$-positive or $\mathrm{CH}_{4}$-positive breath test are shown in Table 2 .

No statistical differences were seen between dysbiosis and non-dysbiosis groups for the type of reported symptoms, except for gas-related symptoms of belching and bloating. In patients with dysbiosis, $60.3 \%$ reported belching compared to $34.1 \%$ in those without dysbiosis on HMBT $(P=0.01)$, and $74.6 \%$ of patients with dysbiosis reported bloating compared to $48.8 \%$ of patients without dysbiosis $(P=0.01)$. Further analysis determined that total gas production on HMBT was greater in patients reporting bloating (298.4 ppm vs $145.9 \mathrm{ppm}, P=0.002$ ) and patients reporting belching (299.1 ppm vs $202.5 \mathrm{ppm}, P=0.02$ ) compared to patients who did not report bloating or belching, respectively.

Patients were also categorised by the results of their oesophageal $\mathrm{pH}$-metry. A total of $26 / 35$ patients (74.3\%) with reflux hypersensitivity (negative AET and positive symptom association) and 23/33 patients $(69.7 \%)$ with proven GERD (positive AET with or without a positive symptom association) had dysbiosis on HMBT. The prevalence of SIBO in these groups was $57.1 \%$ and $39.4 \%$, and the prevalence of IMO was $37.1 \%$ and $39.4 \%$, respectively.

\section{Discussion}

Our data suggest that nearly two-thirds of patients with reflux symptoms, who have been taking long-term PPIs, have intestinal dysbiosis that is recognisable on HMBT, be it SIBO, IMO or a combination of both. This adds to the growing body of evidence that long-term PPI use may lead to changes in the gut microbiota [7-11].

To our knowledge, these findings are the first to suggest that refractory GERD symptoms may be consequent to changes in the gut microbiota, and there appears to be an increased likelihood of a positive reflux-symptom association in patients with dysbiosis, especially for regurgitation, which is a common indication for antireflux surgery [17]. The presence of SIBO, i.e. a $\mathrm{H}_{2}$-positive breath test, was independently associated with a positive reflux-symptom association for regurgitation. In addition, patients with a
Table 2 Symptoms and $\mathrm{pH}$-impedance characteristics for patients with a $\mathrm{H}_{2}$-positive breath test and patients with a $\mathrm{CH}_{4}$-positive breath test

\begin{tabular}{lllll}
\hline & $\mathrm{H}_{2}$-positive & $P$ value & $\mathrm{CH}_{4}$-positive & $P$ value* \\
\hline$N$ & $41(39.4)$ & & $36(34.6)$ & \\
Symptoms & & & & \\
Heartburn & $27(65.9)$ & 0.68 & $25(69.4)$ & 0.36 \\
Regurgitation & $22(53.7)$ & 0.98 & $18(50.0)$ & 0.57 \\
Chest pain & $14(34.1)$ & 0.80 & $15(41.7)$ & 0.16 \\
Cough & $9(22.0)$ & 0.28 & $11(30.6)$ & 0.66 \\
Belching & $23(56.1)$ & 0.32 & $24(66.7)$ & 0.01 \\
Nausea & $14(34.1)$ & 0.13 & $8(22.2)$ & 0.53 \\
Bloating & $33(80.5)$ & 0.01 & $23(63.9)$ & 0.93 \\
Abdominal pain & $21(51.2)$ & 0.19 & $15(41.7)$ & 0.81 \\
AET $>$ 4.0\% & $13(31.7)$ & 0.99 & $13(36.1)$ & 0.49 \\
Mean (SD) number of reflux episodes & $59.1 \pm 31.0$ & 0.67 & $63.2 \pm 42.7$ & 0.22 \\
Mean (SD) DeMeester score & $11.4 \pm 19.6$ & 0.51 & $11.3 \pm 13.0$ & 0.53 \\
Positive reflux-symptom association & $32(78.0)$ & $<0.001$ & $26(72.2)$ & 0.04 \\
Heartburn SAP & $10(24.4)$ & 0.19 & $7(19.4)$ & 0.82 \\
Regurgitation SAP & $18(43.9)$ & 0.01 & $11(30.6)$ & 0.78 \\
Chest pain SAP & $0(0.0)$ & 0.10 & $3(8.3)$ & 0.08 \\
Cough SAP & $4(3.8)$ & 0.10 & $1(2.8)$ & 0.68 \\
Belching SAP & $15(36.6)$ & 0.11 & $12(33.3)$ & 0.37 \\
\hline
\end{tabular}

Values are expressed as numbers (percentages) unless stated otherwise

$\mathrm{H}_{2}$-positive hydrogen-positive breath test, $\mathrm{CH}_{4}$-positive methane-positive breath test, $\mathrm{AET}$ acid exposure time, $S A P$ symptom association probability

*Using Student's $t$ test and $\chi^{2}$ test between $\mathrm{H}_{2}$-positive and $\mathrm{H}_{2}$-negative groups and $\mathrm{CH}_{4}$-positive and $\mathrm{CH}_{4}$-negative groups 
positive symptom association for regurgitation and belching had greater production of hydrogen on HMBT. Therefore, we postulate that SIBO may be a contributory factor to refractory reflux symptoms owing to endogenous bacterial fermentation in the small bowel. Methanogens can be found in the small bowel but are thought to predominantly overgrow in the colon [18], which may explain why methane production was not associated with reflux.

Furthermore, at 5 years following fundoplication, the prevalence of gas-bloat syndrome is around 40\% [4]. Interestingly, this is similar to the prevalence of SIBO in our study. The cause of gas-bloat syndrome following fundoplication is thought to be secondary to the inability of the gastroesophageal junction to relax in response to gastric distension since gas reflux events are less frequent after a partial fundoplication than after a complete fundoplication [19]. However, the exact pathophysiology of gas bloat is unknown. Our data suggest that gas-related symptoms prior to antireflux surgery may be consequential to SIBO since bloating was independently associated with a $\mathrm{H}_{2}$-positive breath test.

$\mathrm{H}_{2}$ and $\mathrm{CH}_{4}$ are by-products of bacterial metabolism, which are absorbed from the gastrointestinal tract and exhaled in the breath making them exclusive biomarkers of endogenous intestinal bacteria. While a $\mathrm{CH}_{4}$-positive breath test is irrefutable due to the requirement of only one single breath sample measuring $\geq 10 \mathrm{ppm}$, the false-positive rate for a $\mathrm{H}_{2}$-positive breath test with glucose or lactulose is high, especially in the presence of rapid mouth-to-cecum transit time $[20,21]$. Therefore, we opted to use a more conservative cut-off (a rise of $\mathrm{H}_{2}$ within $60 \mathrm{~min}$ as opposed to $90 \mathrm{~min}$ ) to reduce the likelihood of a false-positive SIBO result [15]. The prevalence of SIBO in our study is comparable to that across studies that looked at the association between PPI use and SIBO [22].

HMBT is simple and inexpensive, yet they are not routinely performed in the workup of antireflux surgery patients. Incorporation of breath tests into the workup algorithms of reflux patients under consideration for surgery may be of benefit and guide treatment options. To our knowledge, there is no published data assessing outcomes following SIBO eradication in patients presenting with refractory reflux symptoms either before or after antireflux surgery. However, it is possible that identification and treatment of these patients may avoid the need for surgery or even predict a better side-effect profile following antireflux surgery. Of note, one retrospective study showed approximately $30 \%$ of patients undergoing Nissen fundoplication had SIBO, and these patients had inferior quality of life scores, namely gasrelated symptoms [23].

Prior to antireflux surgery, patients are required to undergo oesophageal $\mathrm{pH}$ testing to provide confirmatory evidence of reflux disease. Consequently, we categorised our patients based on the results of their oesophageal $\mathrm{pH}$ impedance test. The prevalence of SIBO was $57.1 \%$ in the reflux hypersensitivity group and $39.4 \%$ in the proven GERD group. Reflux hypersensitivity was defined by normal acid exposure but a positive correlation between the patient's symptoms and reflux events on $\mathrm{pH}$-impedance monitoring [24]. Patients with proven GERD had an abnormal AET with or without a positive symptom association. Although, studies have shown that patients with a positive reflux-symptom association, independent of AET, have favourable outcomes for antireflux surgery $[25,26]$. Therefore, this study suggests that around 1 in 2 good candidates for antireflux surgery have SIBO. A positive symptom association for regurgitation would typically bolster the decision for antireflux surgery, but we showed that a positive symptom association for regurgitation may be related to $\mathrm{H}_{2}$ production from SIBO. The evaluation of SIBO in patients with postoperative gasbloat symptoms should be considered as a focus for further study.

While SIBO can be difficult to treat, a recent guideline has identified dietary modification and antibiotics can be effective [14]. In a randomised double-blind placebo-controlled trial, patients with abdominal bloating had a positive response to rifaximin and symptom improvement correlated to a reduction in $\mathrm{H}_{2}$-breath excretion [27]. Rifaximin is a non-systematic antibiotic that is superior to other antibiotics for the treatment and retreatment of SIBO [28]. However, one study found that $66 \%$ of irritable bowel syndrome (IBS) patients who did not eliminate $\mathrm{CH}_{4}$ with rifaximin alone were able to normalise HMBT following the addition of neomycin [29].

Rifaximin is mostly reserved for the treatment of traveller's diarrhoea, hepatic encephalopathy and IBS-D. However, Tan et al., found that rifaximin led to relief of belching and postprandial fullness/bloating in patients with functional dyspepsia in the absence of IBS [30]. There is a well-established overlap between GERD and IBS patients due to functional dyspepsia symptoms, namely belching and bloating $[31,32]$. Our study found that belching and bloating were more common in reflux patients with intestinal dysbiosis, and gas production was significantly greater in these patients on HMBT. Changes to the intestinal microbiome appear to play an important role in the aetiology of IBS $[33,34]$. The efficacy of rifaximin in IBS is presumed to be an antibiotic effect on the small intestinal microbiota, especially since it is more efficacious in the presence of bile acids [35]. Hence, the overlap between GERD and IBS may be derived from PPI-induced changes to the proximal intestinal microbiota. This is further supported by Zhong et al., who demonstrated that bacterial load in the duodenum is correlated positively with symptom severity in dyspeptic patients [36].

There were several limitations within this study. First, we did not know the status of intestinal dysbiosis prior to 
PPI therapy, and some patients had been taking PPIs for over 10 years. Second, there was no healthy control group, albeit there is a lack of conclusive data for the prevalence of intestinal dysbiosis in patients not taking PPIs, particularly when considering both SIBO and IMO. The study by Lombardo et al., found the prevalence of SIBO in 50 healthy controls, who had not taken PPIs for at least 10 years, to be $6.0 \%$ on HMBT [9]. Although, this was using glucose, which is considered to be more sensitive for diagnosing SIBO when compared to lactulose [13]. To overcome this, we used a more conservative cut-off time in this study as previously described. Third, there was no outcome data in those who eventually opted for surgical intervention. Hence, we are planning to carry out a prospective study on treating patients with intestinal dysbiosis to see if there is a reduction in reflux symptoms.

Of note, we did not exclude patients with aerophagia, and supragastric belching is thought to be the main determinant of troublesome belching in GERD [37]. However, we only found seven patients who demonstrated pathological supragastric belching and four were in the negative HMBT group [38]. Therefore, the primary cause of belching in reflux patients may be due to fermentative intestinal dysbiosis.

\section{Conclusion}

The prevalence of intestinal dysbiosis is high in patients who are under consideration for antireflux surgery. This study highlights a potentially novel connection between bacterial fermentation patterns and refractory GERD symptoms, namely regurgitation. It adds to the growing body of evidence that gastric acid suppression may alter the intestinal microbiota. Since there appears to be a relationship between SIBO and bloating in antireflux surgery candidates, breath testing could be useful in the pre-surgical workup by determining those who may be more prone to gas-bloat syndrome. These findings warrant further research into the role that changes in the intestinal microbiota, especially untreated SIBO, may have in GERD patients who undergo antireflux surgery. Also, it highlights the need to identify pathways for the treatment of SIBO, either before or after antireflux procedures, or perhaps to help avoid surgery altogether.

Funding This retrospective study was funded by Functional Gut Diagnostics.

\section{Compliance with ethical standards}

Disclosures Anthony Hobson is the cofounder of Functional Gut Diagnostics and has an equity interest in the company. In addition, Jordan Haworth receives income from Functional Gut Diagnostics as a serving employee. The authors Nicholas Boyle and Andres Vales declare that they have no conflict of interest.

Ethical approval The study was a retrospective audit of clinic data, and all patients included in the study had provided written informed consent at the time of testing that their data to be used anonymously for research and audit purposes in line with the Care Quality Commission (UK) guidelines.

Open Access This article is licensed under a Creative Commons Attribution 4.0 International License, which permits use, sharing, adaptation, distribution and reproduction in any medium or format, as long as you give appropriate credit to the original author(s) and the source, provide a link to the Creative Commons licence, and indicate if changes were made. The images or other third party material in this article are included in the article's Creative Commons licence, unless indicated otherwise in a credit line to the material. If material is not included in the article's Creative Commons licence and your intended use is not permitted by statutory regulation or exceeds the permitted use, you will need to obtain permission directly from the copyright holder. To view a copy of this licence, visit http://creativecommons.org/licenses/by/4.0/.

\section{References}

1. Bell R, Lipham J, Louie BE, Williams V, Luketich J, Hill M, Richards W, Dunst C, Lister D, McDowell-Jacobs L, Reardon P, Woods K, Gould J, Buckley FP, Kothari S, Khaitan L, Smith CD, Park A, Smith C, Jacobsen G, Abbas G, Katz P (2019) Magnetic sphincter augmentation superior to proton pump inhibitors for regurgitation in a 1-year randomized trial. Clin Gastroenterol Hepatol. https://doi.org/10.1016/j.cgh.2019.08.056

2. Humphries LA, Hernandez JM, Clark W, Luberice K, Ross SB, Rosemurgy AS (2013) Causes of dissatisfaction after laparoscopic fundoplication: the impact of new symptoms, recurrent symptoms, and the patient experience. Surg Endosc 27(5):1537-1545. https ://doi.org/10.1007/s00464-012-2611-y

3. Grant AM, Cotton SC, Boachie C, Ramsay CR, Krukowski ZH, Heading RC, Campbell MK (2013) Minimal access surgery compared with medical management for gastro-oesophageal reflux disease: five year follow-up of a randomised controlled trial (REFLUX). BMJ Clin Res 346:1908. https://doi.org/10.1136/ bmj.f1908

4. Galmiche JP, Hatlebakk J, Attwood S, Ell C, Fiocca R, Eklund S, Langstrom G, Lind T, Lundell L (2011) Laparoscopic antireflux surgery vs esomeprazole treatment for chronic GERD: the LOTUS randomized clinical trial. JAMA 305(19):1969-1977. https://doi. org/10.1001/jama.2011.626

5. Currie AC, Bright T, Thompson SK, Smith L, Devitt PG, Watson DI (2019) Acceptable outcomes after fundoplication-different views are held by patients, GPs, and surgeons. Dis Esophagus. https://doi.org/10.1093/dote/doz025

6. Kinoshita Y, Ishimura N, Ishihara S (2018) Advantages and disadvantages of long-term proton pump inhibitor use. J Neurogastroenterol Motil 24(2):182-196. https://doi.org/10.5056/jnm18001

7. Jackson MA, Goodrich JK, Maxan M-E, Freedberg DE, Abrams JA, Poole AC, Sutter JL, Welter D, Ley RE, Bell JT, Spector TD, Steves CJ (2016) Proton pump inhibitors alter the composition of the gut microbiota. Gut 65(5):749. https://doi.org/10.1136/gutjn 1-2015-310861

8. Imhann F, Bonder MJ, Vich Vila A, Fu J, Mujagic Z, Vork L, Tigchelaar EF, Jankipersadsing SA, Cenit MC, Harmsen HJM, Dijkstra G, Franke L, Xavier RJ, Jonkers D, Wijmenga C, Weersma 
RK, Zhernakova A (2016) Proton pump inhibitors affect the gut microbiome. Gut 65(5):740. https://doi.org/10.1136/gutjnl-2015310376

9. Lombardo L, Foti M, Ruggia O, Chiecchio A (2010) Increased incidence of small intestinal bacterial overgrowth during proton pump inhibitor therapy. Clin Gastroenterolo Hepatol 8(6):504508. https://doi.org/10.1016/j.cgh.2009.12.022

10. Compare D, Pica L, Rocco A, De Giorgi F, Cuomo R, Sarnelli G, Romano M, Nardone G (2011) Effects of long-term PPI treatment on producing bowel symptoms and SIBO. Eur J Clin Investig 41(4):380-386. https://doi.org/10.1111/j.1365-2362.2010.02419 . $\mathrm{X}$

11. Jacobs C, Coss Adame E, Attaluri A, Valestin J, Rao SS (2013) Dysmotility and proton pump inhibitor use are independent risk factors for small intestinal bacterial and/or fungal overgrowth. Aliment Pharmacol Ther 37(11):1103-1111. https://doi.org/10.1111/ apt.12304

12. Rezaie A, Buresi M, Lembo A, Lin H, McCallum R, Rao S, Schmulson M, Valdovinos M, Zakko S, Pimentel M (2017) Hydrogen and methane-based breath testing in gastrointestinal disorders: the North American Consensus. Am J Gastroenterol 112(5):775-784. https://doi.org/10.1038/ajg.2017.46

13. Khoshini R, Dai SC, Lezcano S, Pimentel M (2008) A systematic review of diagnostic tests for small intestinal bacterial overgrowth. Dig Dis Sci 53(6):1443-1454. https://doi.org/10.1007/ s10620-007-0065-1

14. Pimentel M, Saad RJ, Long MD, Rao SSC (2020) ACG clinical guideline: small intestinal bacterial overgrowth. Am J Gastroenterol 115(2):165-178. https://doi.org/10.14309/ajg.0000000000 000501

15. Eisenmann A, Amann A, Said M, Datta B, Ledochowski M (2008) Implementation and interpretation of hydrogen breath tests. J Breath Res 2(4):046002. https://doi.org/10.1088/17527155/2/4/046002

16. Gyawali CP, Kahrilas PJ, Savarino E, Zerbib F, Mion F, Smout A, Vaezi M, Sifrim D, Fox MR, Vela MF, Tutuian R, Tack J, Bredenoord AJ, Pandolfino J, Roman S (2018) Modern diagnosis of GERD: the Lyon Consensus. Gut 67(7):1351-1362. https://doi. org/10.1136/gutjnl-2017-314722

17. Stefanidis D, Hope WW, Kohn GP, Reardon PR, Richardson WS, Fanelli RD (2010) Guidelines for surgical treatment of gastroesophageal reflux disease. Surg Endosc 24(11):2647-2669. https ://doi.org/10.1007/s00464-010-1267-8

18. Sahakian AB, Jee SR, Pimentel M (2010) Methane and the gastrointestinal tract. Dig Dis Sci 55(8):2135-2143. https://doi. org/10.1007/s10620-009-1012-0

19. Broeders JA, Bredenoord AJ, Hazebroek EJ, Broeders IA, Gooszen HG, Smout AJ (2012) Reflux and belching after 270 degree versus 360 degree laparoscopic posterior fundoplication. Ann Surg 255(1):59-65. https://doi.org/10.1097/SLA.0b013e3182 389998

20. Lin EC, Massey BT (2016) Scintigraphy demonstrates high rate of false-positive results from glucose breath tests for small bowel bacterial overgrowth. Clin Gastroenterol Hepatol 14(2):203-208. https://doi.org/10.1016/j.cgh.2015.07.032

21. Yu D, Cheeseman F, Vanner S (2011) Combined oro-caecal scintigraphy and lactulose hydrogen breath testing demonstrate that breath testing detects oro-caecal transit, not small intestinal bacterial overgrowth in patients with IBS. Gut 60(3):334-340. https:// doi.org/10.1136/gut.2009.205476

22. Su T, Lai S, Lee A, He X, Chen S (2018) Meta-analysis: proton pump inhibitors moderately increase the risk of small intestinal bacterial overgrowth. J Gastroenterol 53(1):27-36. https://doi. org/10.1007/s00535-017-1371-9
23. Velasco JA, Baltazar-Alba I, Gómez-Hermosillo LF, CasillasMoreno J, Ulloa-Ruiz FF, Godoy-Castro VM, Mercado-Jáuregui LA, Rangel-Orozco MF, Díaz-Aceves PE, Olvera-García VA, Guzmán-Lepe A (2019) Frecuencia de sobrecrecimiento bacteriano de intestino delgado en pacientes con funduplicatura Nissen. Revista Médica 10:131-136

24. Drossman DA (2016) Functional gastrointestinal disorders: history, pathophysiology, clinical features and Rome IV. Gastroenterology. https://doi.org/10.1053/j.gastro.2016.02.032

25. Tolone S, Gualtieri G, Savarino E, Frazzoni M, de Bortoli N, Furnari M, Casalino G, Parisi S, Savarino V, Docimo L (2016) Preoperative clinical and instrumental factors as antireflux surgery outcome predictors. World J Gastrointest Surg 8(11):719-728. https://doi.org/10.4240/wjgs.v8.i11.719

26. Frazzoni M, Piccoli M, Conigliaro R, Manta R, Frazzoni L, Melotti G (2013) Refractory gastroesophageal reflux disease as diagnosed by impedance-pH monitoring can be cured by laparoscopic fundoplication. Surg Endosc 27(8):2940-2946. https://doi. org/10.1007/s00464-013-2861-3

27. Sharara AI, Aoun E, Abdul-Baki H, Mounzer R, Sidani S, Elhajj I (2006) A randomized double-blind placebo-controlled trial of rifaximin in patients with abdominal bloating and flatulence. Am J Gastroenterol 101(2):326-333. https://doi.org/10.111 1/j.1572-0241.2006.00458.x

28. Yang J, Lee HR, Low K, Chatterjee S, Pimentel M (2008) Rifaximin versus other antibiotics in the primary treatment and retreatment of bacterial overgrowth in IBS. Dig Dis Sci 53(1):169-174. https://doi.org/10.1007/s10620-007-9839-8

29. Low K, Hwang L, Hua J, Zhu A, Morales W, Pimentel M (2010) A combination of rifaximin and neomycin is most effective in treating irritable bowel syndrome patients with methane on lactulose breath test. J Clin Gastroenterol 44(8):547-550. https://doi. org/10.1097/MCG.0b013e3181c64c90

30. Tan VP, Liu KS, Lam FY, Hung IF, Yuen MF, Leung WK (2017) Randomised clinical trial: rifaximin versus placebo for the treatment of functional dyspepsia. Aliment Pharmacol Ther 45(6):767-776. https://doi.org/10.1111/apt.13945

31. Nastaskin I, Mehdikhani E, Conklin J, Park S, Pimentel M (2006) Studying the overlap between IBS and GERD: a systematic review of the literature. Dig Dis Sci 51(12):2113-2120. https://doi. org/10.1007/s10620-006-9306-y

32. Yarandi SS, Nasseri-Moghaddam S, Mostajabi P, Malekzadeh R (2010) Overlapping gastroesophageal reflux disease and irritable bowel syndrome: increased dysfunctional symptoms. World J Gastroenterol 16(10):1232-1238. https://doi.org/10.3748/wjg. v16.i9.1232

33. Chey WD, Kurlander J, Eswaran S (2015) Irritable bowel syndrome: a clinical review. JAMA 313(9):949-958. https://doi. org/10.1001/jama.2015.0954

34. Kennedy PJ, Cryan JF, Dinan TG, Clarke G (2014) Irritable bowel syndrome: a microbiome-gut-brain axis disorder? World J Gastroenterol 20(39):14105-14125. https://doi.org/10.3748/wjg.v20. i39.14105

35. Darkoh C, Lichtenberger LM, Ajami N, Dial EJ, Jiang Z-D, DuPont HL (2010) Bile acids improve the antimicrobial effect of rifaximin. Antimicrob Agents Chemother 54(9):3618-3624. https ://doi.org/10.1128/AAC.00161-10

36. Zhong L, Shanahan ER, Raj A, Koloski NA, Fletcher L, Morrison M, Walker MM, Talley NJ, Holtmann G (2017) Dyspepsia and the microbiome: time to focus on the small intestine. Gut 66(6):1168. https://doi.org/10.1136/gutjnl-2016-312574

37. Kessing BF, Bredenoord AJ, Velosa M, Smout AJPM (2012) Supragastric belches are the main determinants of troublesome belching symptoms in patients with gastro-oesophageal reflux 
disease. Alimen pharmacol Ther 35(9):1073-1079. https://doi. org/10.1111/j.1365-2036.2012.05070.x

38. Koukias N, Woodland P, Yazaki E, Sifrim D (2015) Supragastric belching: prevalence and association with gastroesophageal reflux disease and esophageal hypomotility. J Neurogastroenterol Motil 21(3):398-403. https://doi.org/10.5056/jnm15002
Publisher's Note Springer Nature remains neutral with regard to jurisdictional claims in published maps and institutional affiliations. 